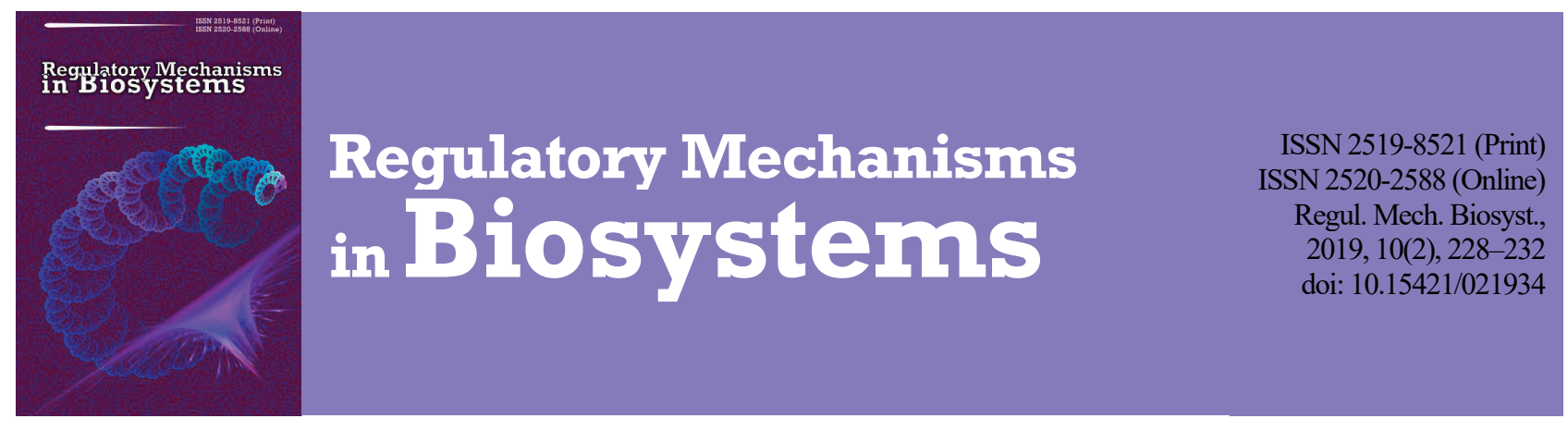

\title{
Combined effect of glyphosate, saccharin and sodium benzoate on the gut microbiota of rats
}

\author{
M. V. Bilan*, M. A. Lieshchova*, N. M. Tishkina*, V. V. Brygadyrenko**** \\ *Dnipro State Agrarian and Economic University, Dnipro, Ukraine \\ **Oles Honchar Dnipro National University, Dnipro, Ukraine
}

Article info

Received 11.03.2019

Received in revised form 16.04.2019

Accepted 20.04.2019

Dnipro State Agrarian and Economic

University, Serhii Efremov st., 25, Dnipro, 49600, Ukraine.

Tel.: +38-056-268-54-17.

E-mail:

lieshchova.m.o@dsau.dp.ua

Oles Honchar Dnipro National University, Gagarin av., 72 , Dnipro, 49010, Ukraine. Tel.: +38-050-93-90-788. E-mail:brigad@ua.fm

\begin{abstract}
Bilan, M. V., Lieshchova, M. A., Tishkina, N. M., \& Brygadyrenko, V. V. (2019). Combined effect of glyphosate, saccharin and sodium benzoate on the gut microbiota of rats. Regulatory Mechanisms in Biosystems, 10(2), 228-232. doi:10.15421/021934

Glyphosate is the main component of many broadly used herbicides due to its safety for humans and animals. It is known that the remains of glyphosate are present in allowable doses in fodders and food products, and, consumrd in low doses, it is found in insignificant amounts in milk, eggs and even in the internal organs (liver, kidneys) of animals. For determining combined impact of glyphosate and the commonest food additives on the composition of microbiota of animals, four groups of laboratory male rats were formed, which during 42 days consumed pure water without any restrictions; $1 \%$ aqueous solution of glyphosate; $1 \%$ solution of glyphosate in combination with $1 \%$ solution of sodium benzoate; $1 \%$ solution of glyphosate with $1 \%$ solution of saccharin. After killing the animals, $1 \mathrm{~g}$ of feces were collected and by serial dilutions with 10-1 to 10-9 sterile physiologic solution, a microbiological analysis was undertaken. Out of each dilution an inoculation of the studied material to the elective growth media was performed, by $0.1 \mathrm{~cm}^{3}$, then the material was incubated in a thermostat $\left(24-72\right.$ hours, temperature $\left.37^{\circ} \mathrm{C}\right)$, the results were recorded after 24-72 h. The microorganisms were identified by studying morphological parameters, tinctorial, cultural and enzymic properties. Results are provided in CFU/g (colony-forming unit per gramm) of feces. The impact of glyphosate and glyphosate with food additives led to no changes in the number of Escherichia coli and emergence of this species of microorganism with changed enzymic activity. Also no changes occurred in the number of microorganisms of Bifidobactrium and Lactobacillus spp. Addition of glyphosate, and also glyphosate in combination with saccharin to the diet contributes to broader reproduction of microorganisms of Klebsiella, Citrobacter, Enterobacter and Pseudomonas genera. Mixtures of glyphosate and food additives allow conditionally pathogenic yeast-like Candida fungi (Candida glabrata and C. albicans) to spread more widely in the intestine. Significant fluctuations in the number of Enterococcus spp. bacteria genus were observed: by 80 times within range of each of the three experimental groups of rats with addition of herbicide with benzoate and saccharin to the diet.
\end{abstract}

Keywords: gut microbiota; glyphosate; herbicides; saccharin; benzoate.

\section{Introduction}

Over the process of evolution, microbial associations which make up the normal gut microbiota have been formed, which is one of the mechanisms of maintaining homeostasis of macroorganisms (Prakash et al., 2011; Molozhavaya et al., 2016). The main functions of the microbiota are considered as follows: role in the process of development of a healthy organism, formation of its immune system and non-specific protection (Ponnusamy et al., 2011; Prakash et al., 2011; Daly et al., 2014; Daly et al., 2016). Furthermore, intestinal microorganisms can intensify or ameliorate the harmful effect of chemical substances due to different mechanisms, presumably interacting with xenobiotics in different ways (Licht \& Bahl, 2018).

Administration of a large amount of antibacterial preparations, irrational and non-balanced diet, stresses, toxic substances in the components of food and food products, which accumulate at all stages of agricultural and industrial production, and other factors can lead to change in the quantitative and qualitative composition of the gut microbiota (Prakash et al., 2011; Rothschild et al., 2018; Licht \& Bahl, 2018).

Also, research has proved the impact of heavy metals, pesticides, nanoparticles, polycyclic aromatic carbohydrates, dioxins, furan, polychlorinated biphenyls and artificial non-calory sweeteners, on the microbiom of the intestine, which is related to the development of metabolic, malignant, inflammatory, or immune diseases (Tsiaoussis et al., 2019).
Using glyphosate in the compound of herbicides over the last four decades has turned out to be efficient (Benbrook, 2016). It is used due to absence of direct risks for health of people and animals or absence of tendency towards bioaccumulation in the trophic networks (Lund-Høie \& Friestad, 1986; Luis et al., 2011; Landrigan \& Belpoggi, 2018). But its application has increasingly fallen under question, and thus its impact on the environment, living organisms and people should be tested (Mao et al., 2018). Data have been obtained showing that the impact of herbicides in doses which are considered safe can change gut microbiota of animals in early stages of the development, especially before attaining sexual maturity (Mao et al., 2018).

The most frequently used food additives are preservatives, sweeteners, stabilizers and colourings. They are constantly added to food products in allowable concentrations both separately and in combination (Behrens et al., 2017). The impact of these substances on the organisms of humans and animals is described in a number of studies. The most broadly used preservative is sodium benzoate $\left(\mathrm{E}_{211}\right)$ which has antimicrobial and fungicidal effects, significantly inhibiting yeasts and yeast fungi (Adeola \& Aworh, 2013). Non-caloric artificial sweeteners (NAS), particularly saccharin $\left(\mathrm{E}_{954}\right)$, are some of the most broadly used food additives in the world. They are regularly consumed by people suffering obesity and diabetes. Their consumption is considered safe and practical due to their low calorie content, but there are very few scientific studies which have proved this and they often are contradictory (Suez et al., 2014; Ruiz-Ojeda 
et al., 2019). Suez et al. (2014) have demonstrated that consuming typical NAS compositions stimulates the development of glucose intolerance through induction of compositional and functional changes in gut microbiota, which in turn leads to sensitivity of the host to metabolic disorders.

Analysis of the genes of $16 \mathrm{~S}$ ribosomal RNA has revealed 25 main families, including 7 bacterial genera, out of which the dominant are Bacterium, Clostridium and Bacillus. Addition of saccharin to the diet caused significant changes in composition of microbiota, as well as causing changes in its subsequent dynamic (Daly et al., 2015).

Despite the fact that each described substance (glyphosate, sodium benzoate and saccharin) is considered safe in itself, their combined effect on the quantitative composition of the microbiocenosis of the intestine during a specified period has not been studied. Therefore, the objective of our study was determining the impact of glyphosate and its mixture with food additives on the changes of gut microbiota of rats in conditions of a laboratory experiment.

\section{Materials and methods}

The protocol of the study was agreed upon with the Ethics Committee of the Dnipro State Agro-Economic University. The research was performed on male white rats, which were divided into four groups with five animals in each: I group - intact animals (control) which consumed pure water, II group - rats which were given aqueous solution of glyphosate, animals of III and IV groups, which in 1:1 proportion were given aqueous solution of glyphosate with $1 \%$ solution of sodium benzoate and $1 \%$ solution of glyphosate with $1 \%$ aqueous solution of saccharin, respectively. The experiment lasted for 42 days. The methods of conducting the experiments are described in previous articles (Lieshchova et al., 2018, 2019).

For laboratory study, we took $1 \mathrm{~g}$ of feces into a sterile vessel with tightly closable cap plug. Microbiological analysis of the fecal samples, pre-suspended in a test tube with $1.0 \mathrm{~cm}^{3}$ of sterile normal saline, was made by series of dilutions from $10^{-1}$ to $10^{-9}$. Then, out of each dilution, using a pipette we made an inoculation of the examined material to elective growth media, by $0.1 \mathrm{~cm}^{3}$ each time. Then, we performed incubation in a thermostat for $24-72$ hours at temperature of $37^{\circ} \mathrm{C}$. Results were recorded after 24-72 hours. The isolated microorganisms were identified according to examination of morphological parameters, tinctorial, cultural and enzymic properties. Results are given in CFU/g (Colony-forming units per gram) of feces. For reliability, for each genus of microorganisms from the dilutions we studied, we conducted microscopy of the smears stained according to Gram with the purpose of confirming correctness of the identification.

The data were analyzed using Statistica 6.0 (StatSoft Inc., USA) program. In the diagrams, the small squares show the median, the large rectangles show the $25 \%$ and $75 \%$ quartiles, the vertical lines show $95 \%$ of the variation, the stars and circles show the outliers.

\section{Results}

The conducted studies have determined the main representatives of the intestinal microbiome of the tested animals (Fig. 1): bacteria of Bifidobacterium, Lactobacillus, Lactococcus, Escherichia, Proteus, Enterococcus, Citrobacter, Klebsiella, Enterobacter, Clostridium, Staphylococcus, Candida genera. The total number of whole Escherichia coli in different variants of the experiment did not change reliably (Fig. 1a), though addition of glyphosate and sacchrain, glyphosate and benzoate to the diet caused increase in the number of these bacteria by ten-twenty times in one animal. No E. coli with changed enzymic activity, and also no lactosegenerative and hemolyzing forms of this species were found in any of the experimental animals.

The number of microorganisms of the Bifidobactrium genus corresponded to the literature data (Putnikov et al., 2015; Makarova et al., 2019) and was within physiological values of the norm (Fig. 2b). The same results were obtained for Lactobacillus spp. bacteria, except for the variants of the experiment with glyphosate and benzoate and only with glyphosate; in two animals, the number of Lactobacillus spp. was higher than the norm's threshold (Fig. 2c). In the variants of the experi- ment with glyphosate and saccharin, only two rats were observed to have the number of Lactococcus spp. (Fig. $2 d$ ) below the lower threshold of the norm. The number of bacteria of the Proteus genus, saprophyte representatives of Staphylococcus genus (Staphylococcus epidermidis and S. saprophyticus) and pathogenic (S. aureus), bacteria of the Clostridium genus did not reliably change with addition of herbicide and food additives to the diet (Fig. 2e, $f, g, h$ ).

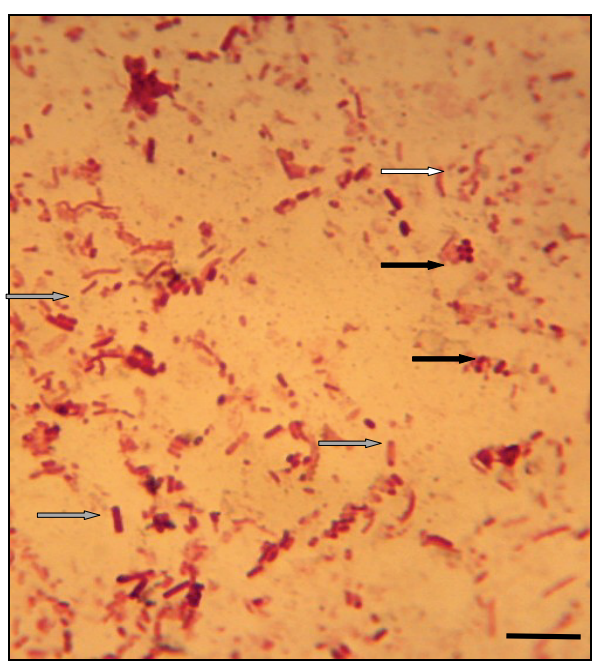

Fig. 1. Microscopic image of the intestinal microbiome in the examined rats. Staining according to Giemsa: grey arrow - bacilliform bacteria with different shapes of the ends of the cell; black arrow - spherical bacteria; white arrows - spiral bacteria; bar $-5 \mu \mathrm{m}$

We observed significant fluctuations in the number of bacteria of Enterococcus spp. (Fig. 2i): by 80 times within each of the three experimental groups of rats, to whose water herbicide with benzoate was added. In two animals of the control, out of the conditionally pathogenic microorganisms of the Enterobacteriaceae family, microorganisms of Enterobacter genus in the amount up to $10^{4} \mathrm{CFU} / \mathrm{g}$ were isolated. In the variant of the experiment with glyphosate and saccharin, in one animal, we found three genera of conditionally pathogenic bacteria: Klebsiella spp., Citrobacter spp. and Enterobacter spp. $-10^{6}, 10^{6}$ and $10^{7} \mathrm{CFU} / \mathrm{g}$, respectively, which was higher than acceptable values. In the variant of the experiment with glyphosate, microorganisms of Klebsiella spp. were found in two rats $\left(4 \times 10^{6}\right.$ and $\left.9 \times 10^{4} \mathrm{CFU} / \mathrm{g}\right)$, Citrobacter spp. in one animal $\left(9 \times 10^{4} \mathrm{CFU} / \mathrm{g}\right)$, and Enterobacter spp. in another animal $\left(1 \times 10^{6} \mathrm{CFU} / \mathrm{g}\right)$. In the variant with glyphosate and benzoate, the total amount of conditionally pathogenic microorganisms of the Enterobacteriaceae family was up to $10^{4} \mathrm{CFU} / \mathrm{g}$.

Furthermore, two of the examined animals in the variant of the experiment with glyphosate and saccharin were observed to have $10^{6}$ CFU/g of bacteria of the Pseudomonas genus, which was higher than reference-ranges of physiological values.

In the control group of rats, the number of Candida glabrata and C. albicans yeast-like fungi (Fig. 3) in the examined samples of feces correlates with the literature data (Prakash et al., 2011; Lozano et al., 2018). In the group to whose diet glyphosate was added, one animal was observed to have $C$. albicans $(1,000 \mathrm{CFU} / \mathrm{g})$. With combined use of glyphosate and benzoate, C. glabrata and C. albicans were found in three experimental animals (200-8,000 CFU/g). C. glabrata and $C$. albicans were found in two animals $\left(500\right.$ and $\left.5.5 \times 10^{5} \mathrm{CFU} / \mathrm{g}\right)$ which received the diet with glyphosate and saccharin. Thus, mixtures of the studied herbicide with food additives allow yeast-like fungi of the Candida genus to colonise the intestine.

\section{Discussion}

Food additives have a significant effect on vital activity of nematodes, intestinal parasites of vertebrates, and also invertebrates which randomly consume food additives in places of accumulation of household and food wastes (Boyko \& Brygadyrenko, 2016, 2017, 2018; Martynov \& Brygadyrenko, 2017). Non-calorie sweeteners stimulate 
development of intolerance to glucose through changes in the gut microflora and resulting inflammatory processes in the organs (Suez et al., 2014; Nettleton et al., 2016; Bian et al., 2017). In a study of stimulation of consumption of some substances (ethanol and nicotine) by sweeteners, experiments on mice revealed that saccharin reduced the number of microorganisms of the Clostridium genus (Labrecque et al., 2015).
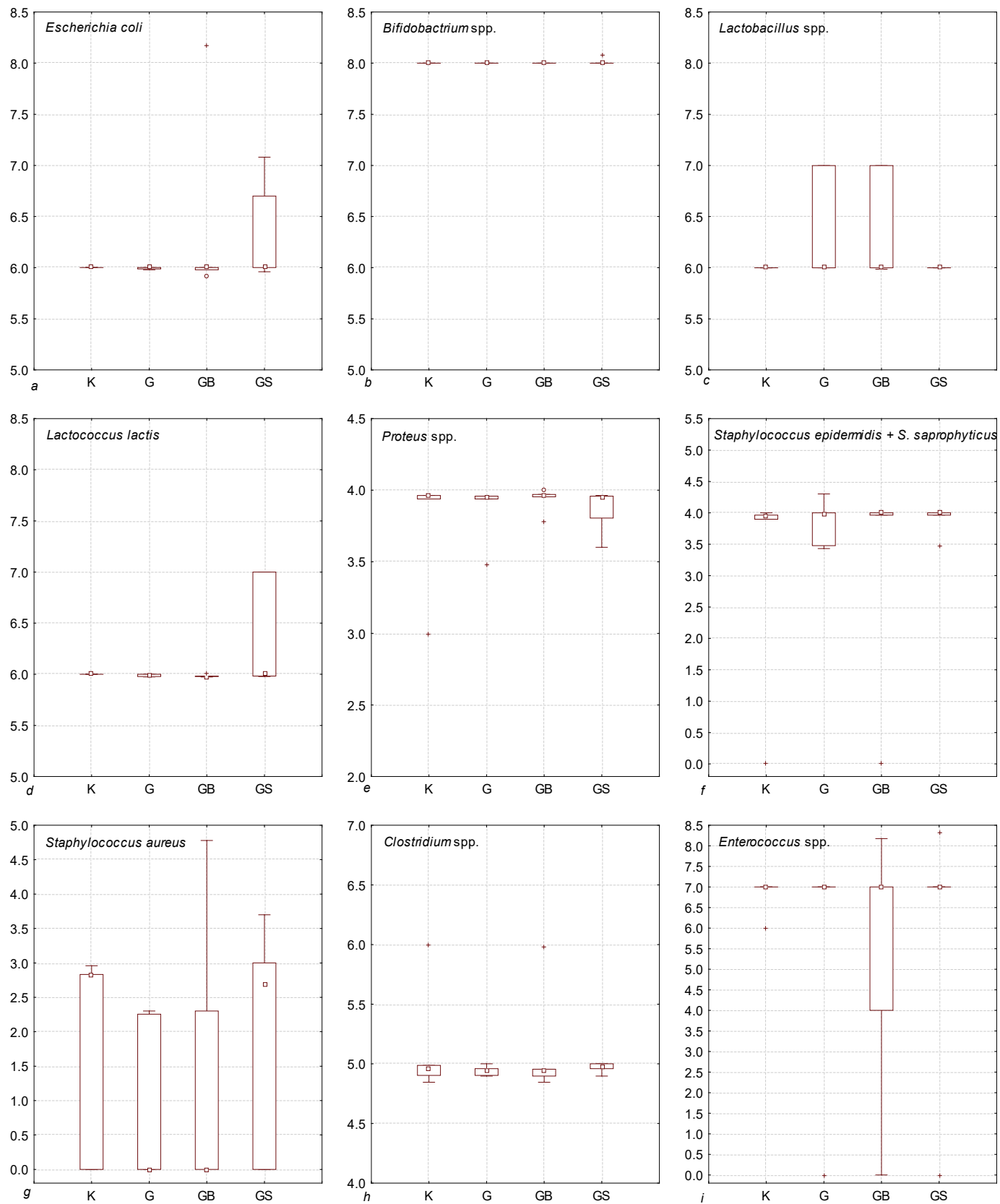

Fig. 2. Change in the number of particular groups of bacteria in the intestine of rats in the conditions of adding glyphosate, benzoate and saccharin to the $\operatorname{diet}(\mathrm{x} \pm \mathrm{SD}, \mathrm{n}=5$, duration of the experiment was 42 days): $a-i$-groups of bacteria indicated in figure; along the abscissa axis - groups of animals: $K$ - control group of rats, $G$ - group of animals for which only glyphosate herbicide was added to the drinking water $(1.0 \%$ of the water mass), $G B$ - group of rats for which glyphosate herbicide (1.0\%) benzoate preservative $(1.0 \%)$ were added to the water, $G S$ - group of rodents for which glyphosate $(1.0 \%)$ and saccharin sweetener $(1.0 \%)$ were added to the water; the ordinate axis shows common $\log _{2}$ arithm $\left(\log _{10} n\right)$ of the number of bacteria per 1 gram of feces; small squares show the median, the large rectangles show the $25 \%$ and $75 \%$ quartiles, the vertical lines show $95 \%$ of the variation, the stars and circles show the outliers

Addition of $7.5 \%$ of saccharin to the rats' diet over 10 days caused no changes in total amount of anaerobic microorganisms in the caecum, but led to disappearance of some groups (Anderson \& Kirkland, 1980). In the small intestine of rats that received $2.5 \%$ dose of saccharin (107 $\mathrm{mg}$ in diet), there was observed inhibition of 6 bacterial strains ( 3 species of microorganisms of Lactobacillus genus and 3 strains of E. coli) (Naim et al., 1985). It is also known that saccharin inhibits fermentation of glucose by microbiota of rats (Pfeffer et al., 1985). Addition of saccharin increases the populations of Lactobacillus and concentration of lactic acid in the caecum (Daly et al., 2015). It was proved that regardless of the way of introduction of glyphosate-conteining prepara- tions into organisms of human and animals, its impact can manifest in toxicity, individual disorders of metabolism, teratogenicity, disorders of cell cycle, genetic dysfunctions, endocrinous pathologies (for example, disorders in regulations of sexual functions) (Baran \& Cibiński, 2014).

Glyphosate affect the bacterial symbionts of animals that live near agricultural lands, including bees. Studies of sequencing genome of intestinal bacteria of bees have revealed that all 8 dominating species of bacteria are potentially sensitive to glyphosate. And relative and absolute content of dominant species of the intestinal microbiota reduces in bees affected by the impact of glyphosate even in insignificant concentrations. Researches has also proved that the impact of glyphosate on 
young individuals leads to increase in mortality as a result of influence of Serratia marcescens (Motta et al., 2018).

Aitbali et al., 2018 determined the impact of glyphosate based herbicide on the number and composition of intestinal microbiota of mice: it reduced the number of representatives of Corynebacterium, Firmicutes, Bacteroidetes and Lactobacillus genera. The researchers found that long-term use of this preparation led to increase in anxiety and depression in the tested animals. The obtained results suggest that dysbacteriosis of the intestine can increase changes in the nervous system.

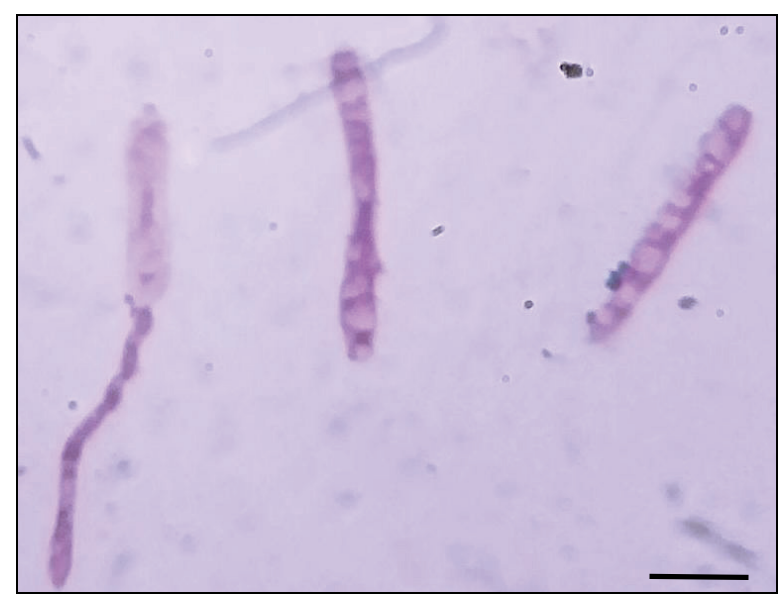

Fig. 3. Pseudohyphae of yeast-like fungus of Candida genus: Staining according to Gram: bar $-10 \mu \mathrm{m}$

Nielsen et al., 2018 observed a limited influence on the composition of the intestinal microbiota in rats during 2 week oral exposure, explaining this by sufficient bioavailability of aromatic aminoacids in the intestine, which weakened the effect of glyphosate which was blocking the the shikimate pathway. At the same time the researchers do not exclude lethal effect of glyphosate, for example, in case of poor nutrition (deficiency of protein) which can cause lower levels of available aminoacids in the intestine.

Impact of small doses of glyphosate and a preparation with its content ("Roundup") on pregnant rats caused significant changes in total bacterial composition of gut microbiota and their progeny. At the same time, the relative number of Bacteroidetes was increased, whereas the number of Lactobacillus was decreased compared to the control (Mao et al., 2018).

In a study of the long-term effect of different doses of Roundup on the gut microbiota of rats, using $16 \mathrm{~S}$ sequencing, a total of 141 families of bacteria were identified. Female rats were observed to have an increase in the number of Bacteroidetes S24-7 microorganisms and reduction of the number of microorganisms of the Lactobacillaceae family. Using the cultural method, direct impact of this preparation on gut microbiota of rats was determined; the cultivated species demonstrated different sensitivity to the preparation. At the same time, an $E$. coli resistant strain was found, which the authors explained by absence of the EPSPS gene (which encodes the target enzyme of glyphosate (Lozano et al., 2018).

After using herbicide and food additives over a short period (42 days) it was determined that in some animals $(80 \%)$, microorganisms of Bifidobacterium, Lactobacillus, Escherichia genera were at the lower level of physiologic values (Putnikov et al., 2015; Makarova et al., 2019). Long-term addition of such or similar preparations to the diet over time can lead to changes in the number and decrease in qualitative composition of normal microflora which provide vital activity of the macroorganism.

Thus, use of herbicide and food additives in diet can contribute to reproduction of pathogenic and conditionally pathogenic microorganisms (staphylococcus, streptococcus, yeast-like fungi, enterobacteria and others) which are present in the macroorganism as facultative and transitional microflora. This can lead (Sekirov et al., 2010; Adeola \& Aworh, 2013; Suez et al., 2014; Nettleton et al., 2016) to possible pathologies in the gastrointestinal tract, diseases of cardio-vascular system, disorder in metabolism, allergies and autoimmune diseases.

\section{Conclusions}

Short-term use of herbicides and food additives in the diet of laboratory animals did not significantly change the quantity of normal gut microflora (bacteria of Bifidobactrium, Lactobacillus genera), but contributed to reproduction of conditionally pathogenic enterobacteria of Klebsiella, Citrobacter and Enterobacter genera, yeast-like fungi of Candida genus, Staphylococcus aureus microorganisms and bacteria of the Pseudomonas genus.

The article is a part of the scientific study "Bioindication as the basis of optimizing and protecting valley-terrace landscapes of the steppe zone of Ukraine in conditions of anthropogenic-climatic changes", Number of state registration is $0118 \mathrm{U} 003303$.

\section{References}

Adeola, A. A., \& Aworh, O. C. (2013). Effects of sodium benzoate on storage stability of previously improved beverage from tamarind (Tamarindus indica L.). Food Science and Nutrition, 2(1), 17-27.

Aitbali, Y., Ba-M'hamed, S., Elhidar, N., Nafis, A., Soraa, N., \& Bennis, M. (2018). Glyphosate based herbicide exposure affects gut microbiota, anxiety and depression-like behaviors in mice. Neurotoxicology and Teratology, 67, 4449.

Anderson, R. L., \& Kirkland, J. J. (1980). The effect of sodium saccharin in the diet on caecal microflora. Food and Cosmetics Toxicology, 18(4), 353-355.

Baran, M. J., \& Cibiński, M. (2014). Glyphosate-based phospho-organic herbicides - an outline of action, metabolism and the selected effects on humans and other organisms. Archives of Physiotherapy and Global Researches, 18(1), 35- 45.

Behrens, M., Blank, K., \& Meyerhof, W. (2017). Blends of non-caloric sweeteners saccharin and cyclamate show reduced off-taste due to TAS2R bitter receptor inhibition. Cell Chemical Biology, 24(10), 1199-1204.

Benbrook, C. M. (2016). Trends in glyphosate herbicide use in the United States and globally. Environmental Sciences Europe, 28, 3

Bian, X., Tu, P., Chi, L., Gao, B., Ru, H., \& Lu, K. (2017). Saccharin induced liver inflammation in mice by altering the gut microbiota and its metabolic functions. Food and Chemical Toxicology, 107, 530-539.

Boyko, A. A., \& Brygadyrenko, V. V. (2016). Influence of water infusion of medicinal plants on larvae of Strongyloides papillosus (Nematoda, Strongyloididae). Visnyk of Dnipropetrovsk University. Biology, Ecology, 24(2), $519-525$.

Boyko, A. A., \& Brygadyrenko, V. V. (2017). Changes in the viability of Strongyloides ransomi larvae (Nematoda, Rhabditida) under the influence of synthetic flavourings. Regulatory Mechanisms in Biosystems, 8(1), 36-40.

Boyko, O. O., \& Brygadyrenko, V. V. (2018). The impact of certain flavourings and preservatives on the survivability of larvae of nematodes of Ruminantia. Regulatory Mechanisms in Biosystems, 9(1), 118-123.

Daly, K., Darby, A. C., \& Shirazi-Beechey, S. P. (2016). Low calorie sweeteners and gut microbiota. Physiology and Behavior, 164, 494-500.

Daly, K., Darby, A. C., Hall, N., Nau, A., Bravo, D., \& Shirazi-Beechey, S. P. (2014). Dietary supplementation with lactose or artificial sweetener enhances swine gut Lactobacillus population abundance. British Journal of Nutrition, 111(S1), 30-35.

Daly, K., Darby, A. C., Hall, N., Wilkinson, M. C., Pongchaikul, P., Bravo, D., \& Shirazi-Beechey, S. P. (2015). Bacterial sensing underlies artificial sweetener-induced growth of gut Lactobacillus. Environmental Microbiology, 18(7), 2159-2171.

Labrecque, M. T., Malone, D., Caldwell, K. E., \& Allan, A. M. (2015). Impact of ethanol and saccharin on fecal microbiome in pregnant and non-pregnant mice. Journal of Pregnancy and Child Health, 2, 5 .

Landrigan, P. J., \& Belpoggi, F. (2018). The need for independent research on the health effects of glyphosate-based herbicides. Environmental Health, 17, 51.

Licht, T. R., \& Bahl, M. I. (2018). Impact of the gut microbiota on chemical risk assessment. Current Opinion in Toxicology, in press.

Lieshchova, M. A., Brygadyrenko, V. V., Tishkina, N. M., Gavrilin, P. M., \& Bohomaz, A. A. (2019). Impact of polyvinyl chloride, polystyrene, and polyethylene on the organism of mice. Regulatory Mechanisms in Biosystems, 10(1), 50-55.

Lieshchova, M. A., Tishkina, N. M., Bohomaz, A. A., Gavrilin, P. M., \& Brygadyrenko, V. V. (2018). Combined effect of glyphosphate, saccharin and sodium benzoate on rats. Regulatory Mechanisms in Biosystems, 9(4), 591-597.

Lozano, V. L., Defarge, N., Rocque, L. M., Mesnage, R., Hennequin, D., Cassier, R., de Vendomois, J. S., Panoff, J. M., Seralini, G. E., \& Amiel, C. (2018). 
Sex-dependent impact of Roundup on the rat gut microbiome. Toxicology Reports, 5, 96-107.

Luis, G., Solange, M., \& Mir, L. (2011). Effects of herbicide glyphosate and glyphosate-based formulations on aquatic ecosystems. Herbicides and Environment, 16, 343-368.

Lund-Høie, K., \& Friestad, H. O. (1986). Photodegradation of the herbicide glyphosate in water. Bulletin of Environmental Contamination and Toxicology, 36(1), 723-729.

Makarova, M., Kryshen, K., Alyakrinskaya, A., Rybakova, A., \& Makarov, V. (2019). Characteristics of the intestinal microflora in humans and laboratory animals. International Bulletin of Veterinary Medicine, 4, 97-105.

Mao, Q., Manservisi, F., Panzacchi, S., Mandrioli, D., Menghetti, I., Vornoli, A., Bua, L., Falcioni, L., Lesseur, C., Chen, J., Belpoggi, F., \& Hu, J. (2018). The Ramazzini Institute 13-week pilot study on glyphosate and Roundup administered at human-equivalent dose to Sprague Dawley rats: Effects on the microbiome. Environmental Health, 17, 50.

Martynov, V. O., \& Brygadyrenko, V. V. (2017). The influence of synthetic food additives and surfactants on the body weight of larvae of Tenebrio molitor (Coleoptera, Tenebrionidae). Biosystems Diversity, 25(3), 236-242.

Molozhavaya, O. S., Ivahnjuk, T. V., Makarenko, A. N., \& Broz, R. V. (2016). Physiological functions of intestinal microflora in normal and pathological variants. Actual Problems of the Modern Medicine, 56, 333-340.

Motta, E. V. S., Raymann, K., \& Moran, N. A. (2018). Glyphosate perturbs the gut microbiota of honey bees. Proceedings of the National Academy of Sciences, 115(41), 10305-10310.

Naim, M., Zechman, J. M., Brand, J. G., Kare, M. R., \& Sandovsky, V. (1985). Effects of sodium saccharin on the activity of trypsin, chymotrypsin, and amylase and upon bacteria in small intestinal contents of rats. Experimental Biology and Medicine, 178(3), 392-401.

Nettleton, J. E., Reimer, R. A., \& Shearer, J. (2016). Reshaping the gut microbiota: Impact of low calorie sweeteners and the link to insulin resistance? Physiology and Behavior, 164, 488-493.

Nielsen, L. N., Roager, H. M., Casas, M. E., Frandsen, H. L., Gosewinkel, U., Bester, K., Licht, T. R., Hendriksen, N. B., \& Bahl, M. I. (2018). Glyphosate has limited short-term effects on commensal bacterial community composi- tion in the gut environment due to sufficient aromatic amino acid levels. Environmental Pollution, 233, 364-376.

Pfeffer, M., Ziesenitz, S. C., \& Siebert, G. (1985). Acesulfame K, cyclamate and saccharin inhibit the anaerobic fermentation of glucose by intestinal bacteria. Zeitschrift für Ernährungswissenschaft, 24(4), 231-235.

Ponnusamy, K., Choi, J. N., Kim, J., Lee, S.-Y., \& Lee, C. H. (2011). Microbial community and metabolomic comparison of irritable bowel syndrome faeces. Journal of Medical Microbiology, 60(6), 817-827.

Prakash, S., Rodes, L., Coussa-Charley, M., \& Tomaro-Duchesneau, C. (2011) Gut microbiota: Next frontier in understanding human health and development of biotherapeutics. Biologics: Targets and Therapy, 5, 71-86.

Putnikov, A. V., Holota, Y. V., Sergeychuk, T. M., Ostapchuk, A. M., Zakordonets, L. V., Ostapchenko, L. I., \& Tolstanova, G. M. (2015). Quantitative and functional characteristics of rat intestinal microbiota. Microbiology and Biotechnology, 2, 89-100.

Rothschild, D., Weissbrod, O., Barkan, E., Kurilshikov, A., Korem, T., Zeevi, D., Costea, P. I., Godneva, A., Kalka, I. N., Bar, N., Shilo, S., Lador, D., Vila, A. V., Zmora, N., Pevsner-Fischer, M., Israeli, D., Kosower, N., Malka, G., Wolf, B. C., Avnit-Sagi, T., Lotan-Pompan, M., Weinberger, A., Halpern, Z., Carmi, S., Fu, J., Wijmenga, C., Zhernakova, A., Elinav, E., \& Segal, E. (2018). Environmental factors dominate over host genetics in shaping human gut microbiota. Nature, 555(7695), 210-215.

Ruiz-Ojeda, F. J., Plaza-Díaz, J., Sáez-Lara, M. J., \& Gil, A. (2019). Effects of sweeteners on the gut microbiota: A review of experimental studies and clinical trials. Advances in Nutrition, 10(1), 31-48.

Sekirov, I., Russell, S. L., Antunes, L. C. M., \& Finlay, B. B. (2010). Gut microbiota in health and disease. Physiological Reviews, 90(3), 859-904.

Suez, J., Korem, T., Zeevi, D., Zilberman-Schapira, G., Thaiss, C. A., Maza, O., Israeli, D., Zmora, N., Gilad, S., Weinberger, A., Kuperman, Y., Harmelin, A., Kolodkin-Gal, I., Shapiro, H., Halpern, Z., Segal, E., \& Elinav, E. (2014). Artificial sweeteners induce glucose intolerance by altering the gut microbiota. Nature, 514(7521), 181-186.

Tsiaoussis, J., Antoniou, M. N., Koliarakis, I., Mesnage, R., Vardavas, C. I., Izotov, B. N., Psaroulaki, A., \& Tsatsakis, A. (2019). Effects of single and combined toxic exposures on the gut microbiome: Current knowledge and future directions. Toxicology Letters, 312, 72-97. 